\title{
Matemática elementar e saber pedagógico de conteúdo - estabelecendo relações
}

\author{
Leticia Rangel Victor Giraldo Nelson Maculan
}

\begin{abstract}
Resumo
Este trabalho tem como objetivo investigar a identificação de partes elementares da Matemática (no sentido de Klein, [9], [10], [11]) por professores da escola básica, e as possíveis implicações dessa identificação para a construção do saber pedagógico de conteúdo (no sentido de Shulman, [14]). A pesquisa foi desenvolvida a partir de um estudo coletivo com um grupo de professores, em torno do tema números racionais.
\end{abstract}

Palavras-chave: saber pedagógico de conteúdo, elementarização; números racionais.

\section{Abstract}

This work aims to investigate the identification of elementary parts of Mathematics (in Klein's sense, [9], [10], [11]) by elementary school teachers, and the possible implications of this identification for the construction of content pedagogical knowledge (in Shulman's sense, [14]). The research was developed from a collective study with a group of teachers, around the theme of rational numbers.

Keywords: pedagogical content knowledge, elementarization; rational numbers.

\section{Introdução}

É inequívoco que a atividade de ensino de Matemática na escola básica exige do professor conhecimentos sobre o conteúdo a ser ensinado e sobre pedagogia. As formas como esses conhecimentos se articulam, são construídos e são acionados ao longo da formação e da prática do professor têm despertado intensa discussão na literatura de pesquisa na área nas últimas décadas. Essas questões têm implicações importantes nos modelos de formação de professores de Matemática ([1], [4]) ,

Temos mais a compreender sobre como a formação do professor pode ter uma intervenção efetiva no complexo processo de aprender a ensinar matemática, que, muito frequentemente, é mais influenciado pelas experiências anteriores dos professores como aprendizes ou por contextos de seu trabalho profissional ${ }^{1}$ ([4, p3], tradução nossa).

1 "We have more to understand about how teacher education can be an effective intervention in the complex process of learning to teach mathematics, which is all too often most influenced by teachers' prior experiences as learners or by the contexts of their professional work." [4, p3] 
Entretanto, as preocupações quanto ao saber e aos modelos de formação do professor de Matemática não são recentes. Em sua obra, hoje clássica, Matemática Elementar de um Ponto de Vista Superior, publicada pela primeira vez há mais de um século, o matemático alemão Felix Klein constata uma ruptura entre a matemática escolar, aquela ensinada na escola básica, e a matemática acadêmica universitária. Klein identifica essa ruptura como uma dupla descontinuidade na formação inicial do professor de Matemática: por um lado, entre a matemática estudada no curso universitário e aquela anteriormente aprendida como aluno no ensino básico; e, por outro, entre a matemática do curso universitário e aquela a ser posteriormente ensinada na escola básica. Sobre o saber de conteúdo necessário para o ensino, Klein entende que o professor deve não somente ter conhecimento específico sobre os conceitos e as teorias que ensina, mas também saber relacioná-los e articulá-los, compreender sua natureza científica e sua evolução histórica, de forma a desenvolver uma visão ampla o suficiente para situá-los no panorama da Matemática como ciência. As ideias pioneiras Klein inspiraram a ICMI (International Comission on Mathematical Instruction) e a IMU (International Mathematical Union) a lançar em 2008 - ano em que se celebrou o centenário da primeira edição da obra Matemática Elementar de um Ponto de Vista Superior - o Klein Project For the $21^{\text {st }}$ Century, com o objetivo de produzir recursos didáticos para a formação de professores no espírito de Felix Klein, tendo como princípio norteador estabelecer conexões entre uma visão ampla da matemática e os conteúdos e suas abordagens na escola básica.

Dentre os autores que têm discutido os conhecimentos necessários para o ensino, destaca-se o trabalho de Shulman ([14], [15]), que propõe a noção de saber pedagógico de conteúdo, caraterizado essencialmente como o conhecimento dos aspectos do conteúdo que o fazem ensinável a outros, isto é, o saber sobre o conteúdo para o ensino. Por sua própria natureza, esta modalidade de saber, ainda que não prescinda de conhecimentos importantes adquiridos na formação inicial do professor, desenvolve-se contínua e permanente ao longo da prática profissional.

Neste trabalho, visamos contribuir para a reflexão acerca da formação do professor de Matemática do ensino básico, apresentando uma investigação com foco no desenvolvimento dos saberes necessários para o ensino. Mais especificamente, investigamos em que medida o reconhecimento de aspectos elementares pode ter implicações na construção do saber pedagógico de conteúdo. O estudo é desenvolvido a partir de uma série de sessões coletivas com um grupo de professores, centradas no tema números racionais. Nas seções a seguir, fazemos uma breve revisão da literatura com especial atenção às ideias de Shulman e de Klein. Em seguida, apresentamos os principais resultados do estudo desenvolvido. A investigação aqui relatada é parte da pesquisa em desenvolvimento para a tese de doutorado da primeira autora, sob a orientação do segundo e do terceiro autores.

\section{O saber matemático para o ensino}

Ainda que o trabalho de Shulman ([14], [15]) não trate especificamente do conhecimento do professor de Matemática, ele tem sido uma referência central para a pesquisa em Educação Matemática (e.g. [3], [8], [13], [17]). Em 1896, no artigo - hoje clássico - Those Who Understand: Knowledge Growth in Teaching, o autor introduz a noção de saber pedagógico de conteúdo, como um domínio especial do conhecimento do professor, que articula pedagogia e conteúdo com vistas ao ensino. Para o autor, este saber: ,

[...] identifica diferentes corpos do conhecimento necessário à docência. Ele representa a combinação de conteúdo e pedagogia em um entendimento de como tópicos específicos, problemas ou questões são organizados, representados e adaptados aos diversos interesses e habilidades dos alunos e apresentados no processo de ensino. ${ }^{2}$ ([15, p8], tradução nossa)

2 “...identifies the distinctive bodies of knowledge for teaching. It represents the blending of content and pedagogy 
Para Shulman, o saber pedagógico de conteúdo não pode ser identificado ao saber de pedagogia nem ao saber de conteúdo, ainda que se articule com essas dimensões do conhecimento. O saber de conteúdo diz respeito exclusivamente à matéria, sem compromissos com o ensino, enquanto o saber pedagógico de conteúdo extrapola o conhecimento do conteúdo disciplinar per se, contemplando a dimensão do saber sobre o conteúdo para o ensino: ,

Em relação ao saber pedagógico de conteúdo, eu incluo, para os tópicos mais regularmente ensinados em uma disciplina, as formas mais eficientes de representação das ideias, as mais poderosas analogias, ilustrações, exemplos, explicações e demonstrações - em resumo, as maneiras de representar e formular a matéria que a tornam compreensível a outros. ${ }^{3}$ ([14, p9], tradução nossa)

Embora o saber de conteúdo seja certamente indispensável à formação do professor, a atividade de ensinar Matemática exige um olhar especial para aspectos particulares do conteúdo, que podem ter pouca relevância para o conhecimento da Matemática per se. Esses aspectos são contemplados pelo saber pedagógico de conteúdo.

Consideremos, por exemplo, o caso da operação de divisão com números naturais. Para o professor, não basta conhecer a definição formal da operação, saber que seu algoritmo usual se baseia na estrutura posicional do sistema de numeração decimal e ser capaz de efetuar esse algoritmo, descrevendo detalhadamente e justificando formalmente cada etapa que o compõe. É necessário, além disso, identificar situações resolvidas por meio da operação de divisão a partir de ideias de repartição e de comparação ou medida; reconhecer a relação intrínseca desta com as demais operações básicas; identificar diferentes processos de decomposições e de reagrupamento da representação decimal dos números que possam ser usados para organizar o algoritmo usual de diferentes maneiras e para compor e justificar outras formas de algoritmos e, sobretudo, reconhecer a relevância de cada um desses aspectos para a aprendizagem e ser capaz de articulá-los para estabelecer estratégias de ensino, levando em conta as especificidades de cada contexto de aprendizagem. Por exemplo, a operação $583 \div 7$ pode ser resolvida de diversas formas, dentre as quais aquelas indicadas na Figura 1.
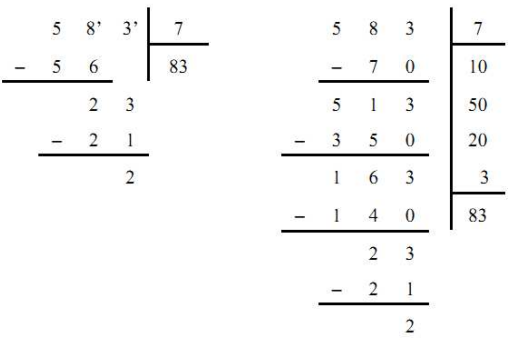

Figura 1: Exemplos de divisões - por ordem e por estimativa.

O algoritmo usual, à esquerda, é frequentemente chamado de algoritmo por ordens, enquanto que o da direita é conhecido como algoritmo por estimativas. Do ponto de vista do conhecimento matemático per se, talvez a única informação relevante seja a de que o algoritmo por ordens otimiza os passos para

into an understanding of how particular topics, problems, or issues are organized, represented, and adapted to the diverse interests and abilities of learners, and presented for instruction." [15, p8]

3 "I include, for the most regularly taught topics in one's subject area, the most useful forms of representation of those ideas, the most powerful analogies, illustrations, examples, explanations, and demonstrations - in a word, the ways of representing and formulating the subject that make it comprehensive to others." [14, p9] 
obter o resultado de uma divisão. No entanto, do ponto do vista do conhecimento matemático para o ensino, é fundamental o reconhecimento de que o uso do algoritmo por estimativas pode contribuir para a compreensão dos alunos sobre a operação de divisão e sobre a natureza do próprio algoritmo e, em alguns casos, pode até ser o mais "econômico" em relação à quantidade de etapas (Por exemplo, no caso de $5050 \div 50$ ). Somente um conhecimento profundo desses aspectos conceituais particulares da operação de divisão e da estrutura de seu algoritmo pode munir o professor com a habilidade de reconhecer a relevância para o ensino do uso de diferentes algoritmos (que podem ser matematicamente equivalentes) e de identificar em que situações pedagógicas o uso de determinado algoritmo é vantajoso.

Nesse sentido, o saber pedagógico de conteúdo é fundamental para a autonomia do professor com respeito a como ensinar e a quando ensinar cada tópico; a avaliar a aprendizagem e a compreensão dos alunos; e a sustentar a tomada de decisões, antes e durante situações reais de sala de aula, quanto e que caminhos e estratégias pedagógicas adotar.

As concepções sobre os saberes necessários para o ensino têm implicações efetivas nos modelos de cursos de formação inicial de professores (Licenciaturas) e, consequentemente, em que professor é formado por esses cursos. Em uma investigação com foco no conhecimento de estudantes de cursos universitários para formação de professores de matemática (equivalentes à nossa licenciatura), [1], propõe uma investigação sobre a operação de divisão. Em relação à divisão envolvendo frações, a pesquisadora propõe aos futuros professores a seguinte questão: ,

\section{Desenvolva uma representação - uma estória, um modelo, uma figura, uma situação do mundo real - para a divisão $1 \frac{3}{4} \div \frac{1}{2}$. [1, p10]}

Dos 18 estudantes participantes, apenas 5 foram capazes de sugerir representações apropriadas; enquanto outros 5 apresentaram representações impróprias, e os 8 restantes declararam-se incapazes de sugerir qualquer forma de representação. Ball destaca que mesmo as 5 respostas consideradas satisfatórias não eram isentas de problemas. De acordo com a pesquisadora, os resultados observados sugerem que o conhecimento desses estudantes sobre a divisão era insuficiente para capacitá-los ao ensino. Em particular, eles associavam a operação de divisão apenas à interpretação como repartição, não considerando a interpretação como comparação ou medida, mais adequada à situação proposta.

Com base nesses resultados, a autora identifica e questiona três suposições que permeiam tacitamente os modelos dos cursos de formação inicial de professores de Matemática nos Estados Unidos: (1) os conteúdos da matemática escolar são simples e comumente entendidos; (2) portanto, não precisam ser reaprendidos no curso universitário; e (3) as disciplinas de matemática universitária são suficientes para equipar os futuros professores com um saber amplo e profundo da matemática escolar. Uma implicação dessas suposições é revelar o caráter inócuo dos cursos de formação inicial de professores de Matemática - é como se esses cursos tivessem pouca relação efetiva com a capacitação dos professores para o ensino, levando-os a buscar outras referências (por exemplo, sua própria experiência como alunos da educação básica) para construir sua prática docente. Para [7], a maioria dos estudos com foco no conhecimento do conteúdo disciplinar do professor de matemática com vistas ao ensino se baliza por descrições de características e/ou demonstrações de sua relação com a aprendizagem dos estudantes. Davis entende que, além de alcançar essas questões, é necessário que a investigação sobre o tema contemple a habilidade dos professores para o ensino e em como ela se estabelece e se desenvolve. Já [7] acredita que "para transformar as salas de aula, é necessário estabelecer concepções de transformação para a matemática dos professores"^4 ([7, pI-64], tradução nossa).

\section{As ideias de Felix Klein}

\footnotetext{
4 “...in order to transform classroom settings, there is a need to design transformative settings for teachers' mathematics." [7, pI-64]
} 
Além do destacado papel de Felix Klein ${ }^{5}$ na pesquisa em Matemática, sua influência e sua contribuição para o ensino da disciplina são inquestionáveis. Em especial, destaca-se em seu legado a obra Matemática Elementar de um Ponto de Vista Superior. A obra originou-se de notas de aulas dadas por Klein para cursos de formação de professores da Universidade de Göttingen. Defensor da percepção da Matemática como um todo orgânico ([9], [16]), Klein preocupou-se com o ensino da disciplina, reconhecendo a importância e a especificidade da formação do professor para o desenvolvimento da Matemática como ciência. O autor identifica um problema que afligia a formação dos professores em sua época - uma ruptura entre a matemática escolar, aquela ensinada nos sistemas de ensino básico e a matemática superior ${ }^{6}$, com referência à produção científica de Matemática. ,

Os jovens estudantes universitários são confrontados com problemas que nada têm a ver com as coisas que estudaram na escola e, naturalmente, esquecem-nas rapidamente. Quando, depois de completarem o curso, se tornam professores confrontados com a necessidade de ensinar a matemática elementar na forma adequada ao grau de ensino, primário ou secundário, a que se dedicam, e como não conseguem estabelecer praticamente nenhuma relação entre esta tarefa e a matemática que aprenderam na universidade, facilmente aceitam o ensino tradicional, ficando os estudos universitários como uma memória mais ou menos agradável que não tem influência na sua forma de ensinar. Klein, [9, p1].

Com a identificação dessa ruptura, Klein aponta uma dupla descontinuidade - por um lado, durante a formação acadêmica do professor, há pouca relação entre a matemática estudada na universidade e aquela anteriormente aprendida no ensino básico e, por outro lado, entre a matemática ensinada pelo professor em sua prática profissional e aquela estudada em sua formação acadêmica. Com sua obra, Klein pretende intervir neste cenário, proporcionando aos futuros professores uma visão ao mesmo tempo profunda e panorâmica da disciplina, que os permita identificar relações e conexões entre os tópicos e entre esses e a matemática que se deve ensinar no ensino básico. ,

O meu objetivo consiste em mostrar-vos sempre as conexões entre problemas de diferentes áreas, o que não acontece de forma suficiente na generalidade dos manuais, e, mais especificamente, sublinhar a relação com os da matemática escolar. Espero que desta forma se torne mais fácil para o leitor adquirir a capacidade que considero o verdadeiro objetivo dos estudos acadêmicos: a de retirar das grandes questôes científicas que nos são oferecidas abundantes estímulos e orientações para o exercício da própria atividade docente. Klein, [9, p2], grifo como no original.

Klein qualifica a percepção hierárquica e estanque entre matemática escolar e matemática universitária como um obstáculo a ser vencido ([16]). Seu entendimento fica claro quando se dirige ao leitor que acompanha as lições que compõem a sua obra, ,

Se não forem suficientemente orientados, se não estiverem bem informados acerca dos elementos intuitivos da matemática bem como das relações vitais entre áreas próximas entre seus ramos e as outras ciências. Se, acima de tudo, não conhecerem o desenvolvimento histórico, seus passos serão muito inseguros. Retirar-se-ão, então, para o campo da matemática pura mais moderna e não serão mais compreendidos na escola secundária ou sucumbirão ao assalto, desistirão do que aprenderam na universidade e, mesmo na vossa maneira de ensinar, deixar-se-ão enterrar na rotina tradicional. Klein, [11, p127].

${ }^{5}$ Felix Christian Klein - 25/04/1849 (ou $5^{2} / 2^{2} / 43^{2}$, como o próprio Klein gostava de ressaltar), Düsseldorf, Alemanha - 22/06/1992, Göttingen, Alemanha.

${ }^{6}$ Neste trabalho, atribui-se o mesmo entendimento às expressões matemática científica, matemática acadêmica, matemática universitária e matemática superior, como referência à produção científica de Matemática, incluindo desde conteúdos ensinados nas disciplinas de conteúdo específico dos cursos de graduação até resultados produzidos em pesquisas de fronteira. 
Klein identifica como matemática elementar aquela que congrega as partes essenciais que encerram a capacidade de sustentar e de estruturar a Matemática. Assim, não há diferença de valor entre o que é elementar e o que é superior - são partes que se fundem e se articulam compondo, com a mesma importância, a Matemática como ciência ([16]). A noção de matemática elementar também é fundamental para a percepção, nos termos de Klein, da relação entre a matemática escolar e a matemática universitária. Klein não se alinha com o entendimento de uma transposição vertical do conhecimento matemático produzido na academia para a escola, à qual caberia apenas o papel passivo de receber e difundir um conhecimento pronto, sem qualquer interferência em sua produção. Segundo Schubring [16], Klein lida com a relação entre esses domínios do conhecimento admitindo a elementarização como um processo de translação histórica, por meio do qual, à medida que a matemática superior é mais bem compreendida, suas partes elementares vão se identificando e se organizando, permitindo o aprofundamento da compreensão e a difusão mais ampla de conceitos e criando assim condições para a produção de novos conhecimentos.Assim, cabe à escola não só difundir o conhecimento elementar, como também contribuir com o próprio processo de elementarização, por meio da criação de categorias próprias para a seleção e adaptação de conteúdos e da avaliação das necessidades do ensino e da formação. Nessa perspectiva, a escola assume um papel de autoria e independência no próprio processo de produção do conhecimento.

\section{A investigação}

Este trabalho pretende contribuir para a reflexão sobre a formação do professor de Matemática e sobre o desenvolvimento do saber pedagógico de conteúdo. Mais especificamente, visamos investigar:

i) como um processo de discussão coletiva centrado no conteúdo do ensino básico pode contribuir para o reconhecimento, por parte do professor, de aspectos elementares desses conteúdos (no sentido de Klein);

ii) em que medida o reconhecimento desses aspectos elementares pode ter implicações para a construção do saber pedagógico de conteúdo (no sentido de Shulman).

A perspectiva de Klein para o ensino de Matemática sugere que o exercício de refletir sobre o próprio saber de conteúdo matemático, reconhecendo partes elementares, a partir dessas partes, sustentar e estruturar a matemática a ser ensinada, pode contribuir para o desenvolvimento de um saber sobre o conteúdo para o ensino - identificado como saber pedagógico de conteúdo por Shulman. Esse é o foco desta investigação.

O tópico escolhido para o estudo foi números racionais, por permear o ensino básico como algo fundamental, sustentar questões relevantes em relação ao seu ensino, além de não intimidar os professores participantes (o que poderia comprometer seu envolvimento na discussão coletiva).

\section{Metodologia}

\subsection{Desenho e desenvolvimento do estudo empírico}

O estudo se deu com o grupo de professores que cursavam a disciplina Tópicos em Ensino de Matemática do curso de Especialização em Ensino de Matemática do Instituto de Matemática da Universidade Federal do Rio de Janeiro, lecionada pela primeira autora no segundo semestre de 2011. Trata-se de uma disciplina eletiva, de ementa variável, o que permitia o desenvolvimento do estudo pretendido. A disciplina ocorreu em sessões semanais com 4 horas de duração, ao longo de 19 semanas.

A turma participantes do estudo era composta por 15 professores com experiência profissional que variava de 1 (um) a 20 (vinte) anos de atuação em sala de aula. Esses professores também apresentavam diversidade em relação à formação inicial, 9 cursaram a licenciatura em um instituição pública, enquanto 6 obtiveram seu diploma em instituições particulares. Na ocasião do desenvolvimento do estudo, todos atuavam em escolas públicas da rede estadual do Rio de Janeiro e/ou da rede municipal da cidade do Rio de Janeiro e, dentre estes, 6 atuavam também em escolas particulares. 
Os dados do estudo foram coletados por meio de gravações em áudio das sessões, anotações sobre o desenvolvimento das sessões por parte da pesquisadora e registros documentais de atividades diversas estabelecidas a partir da discussão, pelo grupo ou pela pesquisadora. A investigação teve como referencial metodológico a noção de Concept Study, proposta por Davis e seus colaboradores (para maiores detalhes, ver, por exemplo, [5], [6], [7]).

\subsection{Análise de dados}

A partir da complexidade das articulações estabelecidas entre o tema central que amparou a discussão (números racionais) e outros tópicos e campos da Matemática, foram identificados três estágios na discussão: Percepções, Estruturas e Panoramas. Esses estágios foram distinguidos, como órbitas estabelecidas a partir do tema central. Assim, o menor nível de articulação foi associado ao primeiro estágio de análise, percepções. Já a órbita mais distante identificada à maior abrangência do tema central, a partir de articulações ampliadas em profundidade, diversidade e alcance. Embora os estágios relativos às órbitas mais interiores tenham de fato se iniciado mais cedo, não pode ser identificada uma ordenação temporal clara, em que cada estágio se sucederia ao término do anterior. Ao contrário, verificam-se interseções entre eles ao longo de todo o estudo. Assim, a variação de um estágio a outro foi mais caracterizada pela qualidade da discussão do que por uma sucessão temporal linear.

$\mathrm{Na}$ seção a seguir, relataremos o desenvolvimento do estudo, com destaque aos estágios identificados. Para cada um desses estágios, relataremos um episódio, escolhido por ser representativo da forma como a discussão foi conduzida, ressaltando o reconhecimento, por parte dos professores, de aspectos elementares dos conteúdos.

\section{Desenvolvimento do estudo}

Inicialmente, os professores foram convidados, por cerca de 3 encontros, a refletir a partir de questões e atividades que tinham como propósito preparar o grupo para uma discussão coletiva, e disparar a reflexão sobre os saberes necessários ao ensino. Essa etapa inicial foi significativamente importante para que a proposta de um estudo coletivo fosse assimilada pelo grupo. Algumas das questões propostas para a discussão foram extraídas de pesquisas que com foco no saber pedagógico de conteúdo. Em destaque no quadro a seguir (Figura 2) a questão que disparou um episódio, escolhido como representativo desta etapa inicial do trabalho. A escolha se justifica pelo impacto que a discussão gerada estabeleceu no desdobramento do estudo.

Suponha que você queira observar se seus alunos são capazes de ordenar números racionais. Qual das seguintes listas de números the daria melhores evidencias sobre a compreensão dos seus alunos?

(a) $0,5 \quad 7 \quad 0,01 \quad 11,4$

(b) $0,60 \quad 2,53 \quad 3,14 \quad 0,45$

$\begin{array}{llll}\text { (c) } 0,6 & 4,25 & 0,565 & 2,5\end{array}$

(d) Essas listas são igualmente boas para avaliar a compreensão dos estudantes sobre a ordenação de números racionais.

Figura 2: Exemplo das questões que orientaram a discussão inicial do estudo. 
por números racionais representados na forma decimal, é possível ordenar os números apresentados nos itens (a) e (b) sem que se leve em conta que se tratam de números não inteiros, ou seja, desprezando-se as vírgulas. Assim, essas listas não são adequadas ao objetivo atribuído à questão. Do ponto de vista do saber de conteúdo per se, é irrelevante o fato de a ordem entre os números ser ou não preservada quando a vírgula é apagada, porém esta questão é crucial para a abordagem pedagógica do conteúdo. Portanto, consideramos que a discussão sobre os objetivos e a adequação dessa questão envolve aspectos do saber pedagógico de conteúdo. Em um primeiro contato com a questão, a maioria dos professores participantes do estudo fez a opção pelo item (d). No entanto, a discussão mais aprofundada sobre a questão, tendo como foco seu objetivo pedagógico, foi fundamental para uma mudança na percepção dos professores. A partir dessa discussão, um dos professores participantes trouxe para a pauta de discussão a questão apresentada na Figura 3, por ter identificado uma "falha" análoga àquela observada na atividade da Figura 2. Essa questão compunha a Prova de Matemática do Exame de Seleção para o Ensino Médio do Centro Federal de Educação Celso Suckow da Fonseca - CEFET/RJ, no ano de 2010.

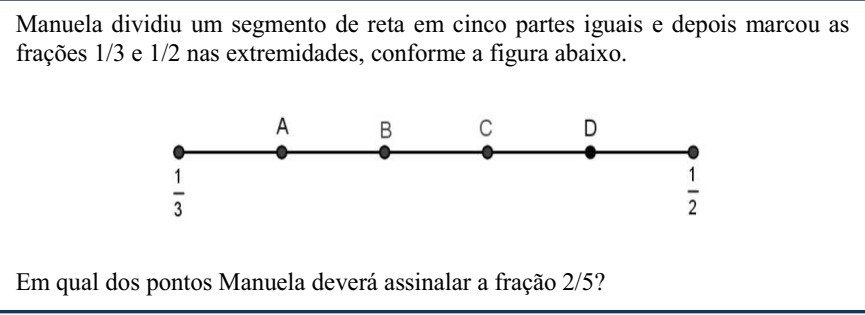

Figura 3: Questão motivadora da reflexão.

Na discussão que se seguiu, o grupo observou que a solução da questão certamente poderia ser estabelecida de diversas formas. Por exemplo, o aluno poderia identificar a distância entre os pontos correspondentes a $1 / 3$ e $1 / 2$, dividir esse valor por cinco, determinando que cada uma das 5 subdivisões do segmento em destaque tem comprimento $1 / 30$, e finalmente identificar que pontos $\mathrm{A}, \mathrm{B}, \mathrm{C}$ e $\mathrm{D}$, correspondem respectivamente aos números 11/30, 2/5, 13/30 e 14/30. Outra solução possível usa resultados próprios de progressões aritméticas, opção em que o problema poderia ser resolvido a partir das fórmulas particulares, portanto, fortemente amparado em procedimentos algébricos. No entanto, os professores observaram que a resposta correta dessa questão poderia ser alcançada por meio de uma resolução errada, que acreditavam ser bastante provável de ser feita pelos estudantes. A partir da sua prática, o grupo avaliou que era bem possível que um estudante identificasse o ponto B como a solução da questão porque o segmento em destaque está dividido em 5 partes e $\mathrm{B}$ corresponde, sob a orientação crescente, à extremidade final do segundo segmento.

Além de discutir a questão em si a partir de seus objetivos, abrangência e adequação, foi proposto como exercício que cada um dos integrantes interviesse na questão resolvendo a "fallha" detectada. Essa intervenção deveria ter como critério a menor alteração possível no enunciado. A visão crítica sobre a questão e a proposta de intervenção de modo a melhorar a questão revelam aspectos importantes que caracterizam o saber pedagógico de conteúdo: a capacidade de análise e a capacidade criativa e autoral sobre a atividade docente. De forma geral, consideramos que a reflexão a partir das questões disparadoras permitiu a identificação explícita pelos participantes de aspectos que caracterizam um saber sobre o conteúdo que é próprio do professor. 


\subsection{Estágio 1 - Percepções}

Para compor este estágio, que é inicial em um Concept Study, os professores foram convidados a refletir a partir da seguinte questão "O que é fundamental no que ensinamos sobre números racionais no ensino básico?". A composição da lista de percepções foi estabelecida a partir de uma intensa discussão do grupo, por dois encontros consecutivos, que teve como referência a experiência da sala de aula. É importante destacar que a observação do estudo revelou que, para compor esse quadro (Figura 4), os professores se pautaram mais no contexto da sala de aula, em sua prática, do que na identificação da relevância do tema para a Matemática. Por exemplo, a discussão que determinou a inclusão do item

\section{Percepções}

- Relacionar parte e todo em situações diversas.

- Compreender a ideia de unidade

- Operações com frações

- Igualdade $\mathrm{x}$ equivalência

- Representação da reta numerada

- Diversos significados de frações - fração como número, como relação parte/todo, como razão e como divisão.

- Mostrar ao aluno que um mesmo número racional tem diversas representações - representação

- Comparação de números racionais na forma decimal

- Comparação de números racionais na forma fracionária

- Dar significado aos números racionais

- Reconhecer os números racionais na forma percentual

- Reconhecer os números inteiros como racionais

- Aproximações

- Dízimas - Em particular o caso do "0,999...”

- "Saber que dados dois números racionais sempre é possível determinar outro entre eles." - Densidade dos racionais.

Figura 4: Quadro percepções do estudo coletivo.

"compreender a ideia de unidade" foi pautada no reconhecimento pelo grupo da dificuldade dos estudantes em resolver problemas em que a unidade não corresponde a um único elemento. Esses problemas são encontrados com alguma frequência nos livros didáticos do ensino básico. O único item cujo reconhecimento do valor para a Matemática ficou explícito e foi preponderante para a inclusão na lista foi o que diz respeito à densidade do conjunto dos racionais. Ainda que alguns professores não associassem a propriedade à definição de conjunto denso, todos concordavam que observar que "dados dois números racionais sempre é possível determinar outro entre eles" era essencial para aprendizagem sobre esses números. A inclusão desse ponto foi pautada mais pelo reconhecimento da relevância do resultado para a Matemática do que pela observação de questões relativas ao ensino desse tópico em sala de aula.

Já no estágio percepções, foram evidenciados e abordados temas que determinariam os demais estágios do estudo, por exemplo, a noção de infinito, a incomensurabilidade, o zero como ente matemático e a exponenciação. 


\subsection{Estágio 2 - Estruturas}

O estágio estruturas ficou caracterizado pela articulação de aspectos matemáticos do conceito de número racional que têm característica estruturante na compreensão do assunto. Em um episódio, escolhido como representativo deste estágio, destacamos a discussão que envolveu a operação de divisão no contexto dos números racionais. Essa discussão foi motivada por um problema trazido por uma das professoras do grupo:

Uma biblioteca tinha todos os seus livros acomodados em 6 estantes completamente cheias. Essas estantes foram substituidas por novas. A capacidade de cada estante nova era igual a $3 / 4$ da capacidade de uma das estantes antigas. Quantas estantes novas serão necessárias para acomodar todos os livros da biblioteca?

A proposta inicial foi estabelecer estratégias diversas de solução para o problema proposto, com atenção à compreensão da operação de divisão, que no contexto dos números racionais, e particularmente no problema em questão, enseja a associação à interpretação como medida. As diversas soluções propostas pelos participantes foram discutidas pelo o grupo, observando a potencialidade para o ensino e para a aprendizagem. É importante observar que, no problema, a unidade corresponde à capacidade de uma estante original. Não é raro que a solução seja apresentada, pelos professores, a partir de uma estratégia correta, mas que evita o cálculo com frações: supõe-se que a capacidade de uma das estantes originais seja, por exemplo, 100 livros. Assim em uma estante nova caberiam 75 livros e a solução seria alcançada pelo resultado de $600 \div 75$. É claro que é essa solução é matematicamente correta e emprega a divisão. No entanto, evita que seja experimentada a divisão envolvendo frações, pois o único cálculo com frações é para determinar 3/4 de 100. Em destaque (Figura 5), a abordagem da solução desse problema a partir de uma representação gráfica, proposta por um dos professores. Foi consenso que esta representação explicita a identificação da interpretação da divisão como medida e a compreensão da operação de divisão no contexto dos números racionais. A discussão sobre esse problema articulou tópicos elementares sobre o ensino do tema: o papel da unidade, a interpretação da divisão como medida e a possibilidade de representação gráfica da divisão - o que para muitos dos participantes se apresentou como uma novidade.
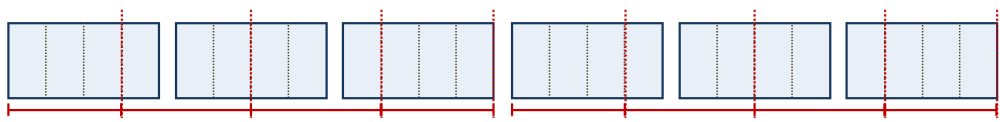

Figura 5: Representação gráfica para a divisão de 6 por $3 / 4$.

Outras discussões que marcaram esse estágio envolveram, por exemplo, a atenção aos conceitos de razão e de fração, a definição de relação de equivalência e a definição formal de número racional.

\subsection{Estágio 3 - Panoramas}

O terceiro estágio identificado neste estudo, panoramas, se caracteriza especialmente por dois aspectos relativos a: (i) a forma como as questões passaram a ser investigadas, revelando explicitamente o reconhecimento dos próprios saberes por parte dos professores; e (ii) as conexões matemáticas estabelecidas, que foram ampliadas em alcance e complexidade, não se limitando apenas ao contexto de números racionais sob a perspectiva do ensino básico. Para representar o desenvolvimento da discussão que caracterizou este estágio, destacamos um episódio que conduziu a discussão durante dois 
encontros consecutivos. Um dos professores, ao final de um dos encontros, apresentou ao grupo o seguinte questionamento: Para fazer cálculos com dízimas ${ }^{7}$, é sempre preciso passar para a forma de fração?

Discutiu-se então que esse questionamento revelava uma dúvida, mas também duas certezas. A dúvida, que estava explícita, era relativa à possibilidade de se efetuar cálculos com números racionais representados como dízimas, isto é, de generalizar de alguma forma os algoritmos usuais das operações para números representados dessa forma. As certezas, implícitas, eram, (i) que todo número racional admitia duas representações, na forma de fração e na forma de expansão decimal e (ii) que na forma de fração os cálculos estavam bem estabelecidos.

Em relação à dúvida, não havia novidade, ela estava sendo exposta e encarada a partir de pesquisa, reflexão e discussão. A novidade emergiu dos questionamentos que se seguiram e que foram bastante ilustrativos para o estudo: "De onde vêm essas certezas? Ou seja, elas foram construídas em que etapa da formação de cada um dos professores?". Essas indagações despertaram uma novidade na abordagem da discussão - questionar uma certeza. Ficava assim evidenciada uma nova forma de percepção do conteúdo: não basta saber, é necessário compreender como esse saber se constitui, qual sua natureza e origem, bem como compreender em que sentido e em que medida esse saber é relevante para a sala de aula.

A resposta ao questionamento também foi reveladora, levando os participantes a reconhecerem que se tratava de uma certeza constituída durante seus próprios estudos no ensino básico e não na formação universitária. Associamos essa constatação à indicação da dupla descontinuidade identificada por [10] e às suposições destacadas por [1], que identificam um afastamento entre o conteúdo de matemática ensinado na graduação e aquele necessário à prática docente na escola básica.

A forma como a questão foi explorada alterou completamente o cenário da discussão. As articulações exigidas foram ampliadas em alcance e complexidade em relação às realizadas até então. Para investigar as questões propostas (estabelecendo matematicamente a equivalência entre representações fracionárias e decimais para números racionais, bem como as limitações dos algoritmos usuais das operações para números com representação decimal infinita) foi necessário mobilizar conhecimentos de álgebra e de análise, bem como observar e recorrer ao rigor e à consistência formal da Matemática. Em particular, a partir desse momento, os professores participantes passaram a buscar espontaneamente, como referência para a discussão, textos acadêmicos. Dessa forma, evidenciaram o reconhecimento de que esses resultados, ainda que admitissem uma abordagem própria para o ensino básico, exigiam e se estabeleciam sob o rigor da formalização Matemática. Assim se destacam, no contexto da álgebra, a construção dos números racionais por classes de equivalência; e no contexto da análise, os resultados que garantem que um número é racional se e somente se sua representação nos sistema de numeração posicional decimal é finita ou periódica. A discussão alcançou ainda a reflexão sobre grandezas incomensuráveis e sobre a construção dos números reais.

A nova perspectiva adquirida pela discussão entre os professores participantes foi identificada às ideias de Klein sobre o reconhecimento de partes elementares da matemática e sobre a percepção dessas partes de um ponto de vista superior, como aspectos formadores de uma visão da matemática ampliada e panorâmica, constituinte do saber pedagógico de conteúdo.

\section{Resultados}

O estudo confirmou a evidência de aspectos implícitos e explícitos do saber pedagógico de conteúdo e do saber de conteúdo dos professores e ficou clara a mudança de atitude dos participantes, que assumiram, ao longo do estudo, uma postura mais investigativa, manifestando, inclusive, a intenção de estender a vivência de uma prática investigativa para suas salas de aula.

\footnotetext{
7 Por dízimas o professor se referia a "dizimas periódicas".
} 
Observamos também que o estudo ofereceu a possibilidade de investigar e explorar, em um processo coletivo, o conhecimento de matemática dos participantes de forma articulada com a sua prática, promovendo uma reconstrução conceitual a partir de um conhecimento anterior.

Com respeito à forma como os questionamentos foram disparados, observou-se que a maior parte das questões emergiu a partir da observação de problemas que os professores resolviam com seus alunos em sala de aula, ou seja, problemas típicos da escola básica. Por um lado, a orientação a partir de problemas próprios do ensino básico revelou que os professores tinham insegurança latente em relação à abordagem formal dos conteúdos matemáticos e que o hábito de refletir sistematicamente a partir de um ponto de vista conceitual era pouco consolidado. Entretanto, por outro lado, essa orientação estabeleceu para o estudo forte vínculo com a prática, o que entendemos que foi fundamental para andamento do estudo.

Com atenção às questões de pesquisa, a investigação se estabeleceu a partir de uma análise das impressões reveladas sobre o saber pedagógico de conteúdo dos professores participantes e nas relações e articulações reveladas na discussão sobre o conteúdo. Mais especificamente, em relação ao saber pedagógico de conteúdo, a análise se pautou na identificação: de dúvidas e de certezas; do nível da escolaridade (ensino básico ou formação superior) a que foi atribuída, pelos participantes, a origem do seu saber sobre o conteúdo; e do grau de complexidade das relações, articulações e conexões estabelecidas.

O processo de investigação com base em dúvidas, e também no questionamento de certezas, revelou-se como uma estratégia positiva para o desenvolvimento do saber do professor. Nesse sentido, o estudo apontou que muitas vezes os professores se surpreendiam com a "descoberta" de resultados matemáticos com os quais vinham lidando por anos sem se dar conta explicitamente, como por exemplo: a associação da operação de divisão a situações de medida ou a relação entre equivalência entre frações e a formalização do conceito de número racional por meio de classes de equivalência. Acreditamos que essa seja uma contribuição importante do estudo, tendo forte implicação para a construção do saber pedagógico de conteúdo dos professores e conferindo-lhes autoridade e protagonismo na construção do próprio saber. Acreditamos que essa atitude consciente dos professores pode contribuir para disparar mudanças em suas práticas de ensino e, consequentemente, para enriquecer a aprendizagem de seus alunos - embora o presente estudo não forneça acesso à verificação de tais aspectos. Este pode ser, portanto, um tema para pesquisas futuras.

Cabe destacar também que a investigação revelou aspectos importantes da formação universitária dos professores participantes (embora este não tenha sido um objetivo inicial da pesquisa). Os questionamentos trazidos para a discussão coletiva emergiam, na maior parte dos casos, de problemas da prática de sala de aula (dificuldades de aprendizagem dos alunos, ou dificuldades dos próprios professores em ensinar os conteúdos). A reflexão conceitual sobre esses questionamentos tinha referência em aspectos da própria pratica (experiências anteriores, livros didáticos) ou na experiência dos professores participantes quando alunos do ensino básico. A ligação dessas questões com resultados matemáticos estudados no curso universitário não apenas não era acionada espontaneamente, como frequentemente causava surpresa aos professores participantes. Este resultado indica pouca influência do curso de Licenciatura na prática de sala de aula dos professores - confirmando resultados observados pela pesquisa internacional em Educação Matemática (por exemplo, [1]) e a atualidade da dupla descontinuidade denunciada por Klein há mais de um século e aponta para a urgência de uma revisão dos modelos adotados para esses cursos no Brasil.

A discussão com o objetivo de reconhecer o que é elementar, não no sentido tradicionalmente estabelecido, como simples ou fácil, mas no sentido de Klein, como partes essenciais que encerram a capacidade de sustentar e de estruturar o conhecimento matemático, revelou para os participantes uma nova perspectiva para a observação do conhecimento pedagógico do conteúdo. Assim, por exemplo, ensinar a equivalência entre frações e associar a operação de divisão à interpretação como medida assumem novas perspectivas. A investigação sugere que, de fato, a busca por aspectos elementares (no sentido de Klein) no conteúdo de matemática do ensino básico determinou um processo de reconstrução do saber pedagógico de conteúdo dos participantes. 
"Realmente, professora, gosto muito dos nossos encontros! O tempo passa tão depressa! Acrescento vários conhecimentos aos meus e refaço outros! Saio pensando em tantos assuntos, que demoro um tempão para querer ligar o rádio do carro, prefiro ficar refletindo sobre tudo que foi conversado em sala de aula! Abraços, Bianca ${ }^{8}$." (grifo nosso)

\section{Referências}

[1] Ball, D. L. The Subject Matter Preparation of Prospective Mathematics Teachers: Challenging The Myths. National Center for Research on Teacher Education, College of Education, Michigan State University, 1988. Disponível em: <http://ncrtl.msu.edu/research.htm>. Acessado em: 12 de março de 2014.

[2] Ball, D. L.; Bass, H. Toward A Practice-Based Theory of Mathematical Knowledge for Teaching. In Davis, B.; Simmt, E. (Eds.), Proceedings of The 2002 Annual Meeting of the Canadian Mathematics Education Study Group, Edmonton, AB: CMESG/GCEDM, p. 3-14, 2003.

[3] Ball, D. L.; Thames, M. H.; Phelps, G. Content Knowledge for Teaching: What Makes it Special?. Journal of Teacher Education, v. 59, n. 5, p. 389-407, 2008.

[4] Even, R.; Ball, D. L. (Eds.) The Professional Education and Development of Teachers of Mathematics - The 15th ICMI Study. New York, NY: Springer, 2009.

[5] Davis, B. Is 1 A Prime Number? Developing Teacher Knowledge through Concept Study. Mathematics Teaching in the Middle School (NCTM), v. 14, n. 2, p. 86-91, 2008.

[6] Davis, B.; Renert, M. Mathematics for Teaching as Shared, Dynamic Participation. For the Learning of Mathematics, v. 29, n. 3, p. 37-43 (Special Issue, guest edited by J. Adler \& D. Ball), 2009.

[7] Davis, B. Concept Studies: Designing settings for Teacher's Disciplinary Knowledge. Proceedings of the $34^{\text {th }}$ Annual Conference of the International Group for the Psychology of Mathematics Education, Minas Gerais, Brasil, v. 1, p. 63-78, 2010.

[8] Doerr, H.; Lesh, R. (2003). Designing Research On Teachers' Knowledge Development. In: Bragg, L.; Campbell, C.; Herbert, G.; Mousley, J. (Eds.), Mathematics Education Research: Innovation, Networking, Opportunity (Proceedings of the 26th annual conference of the Mathematics Education Research Group of Australia, Geelong Sydney, MERGA), p. 262-269, 2003.

[9] Klein, F. Matemática de um Ponto de Vista Superior. Volume I. Parte I Aritmética. SPM, Lisboa, 2009.

[10] Klein, F. Matemática de um Ponto de Vista Superior. Volume I. Parte II Álgebra. SPM, Lisboa, 2010.

[11] Klein, F. Matemática de um Ponto de Vista Superior. Volume I. Parte III Análise. SPM, Lisboa, 2011.

[12] International Mathematical Union. Klein Project. Disponível em: <http://www.didaktik. mathematik.uni-wuerzburg.de/projekt/klein/life.html>. Consultado em: 20 de outubro de 2011.

[13] Krauss, S. et al. Pedagogical Content Knowledge and Content Knowledge of Secondary Mathematics Teachers. Journal of Educational Psychology, v. 100, n. 3, p. 716-725, 2008.

8 A professora identificada aqui como Bianca era uma das participantes com maior tempo de experiência profissional. Essa mensagem foi enviada por ela à pesquisadora ao final de um dos encontros. O nome Bianca é fictício. 
[14] Shulman, L. Those Who Understand: Knowledge Growth in Teaching. Educational Researcher, v. 15, p. $4-14,1986$.

[15] Shulman, L.Knowledge and Teaching: Foundations of The New Feform. Havard Educational Review, 1997, v. 57, p. 1-22, 1987.

[16] Schubring, G. A Matemática Elementar de um Ponto de Vista Superior: Felix Klein e a sua Atualidade. Em: Roque, T.; Giraldo, V. (Eds.), O Saber do Professor de Matemática: Ultrapassando a Dicotomia entre Didática e Conteúdo. Rio de Janeiro: Ciência Moderna, 2014 (a aparecer).

[17] Sztajn, P. O Que Precisa Saber Um Professor de Matemática? Uma Revisão da Literatura Americana dos Anos 90. Em: Educação Matemática em Revista, ano 9, n. 11A, Edição Especial, p. $17-28,2002$.

Leticia Rangel UFRJ <leticiarangel@ufrj.br>

Victor Giraldo UFRJ $<$ victor.giraldo@ufrj.br>

Nelson Maculan UFRJ <maculan@cos.ufrj.br>

Recebido: 2014

Publicado: 2014 